\title{
Por que as taxas de juros são tão elevadas no Brasil? Uma avaliação empírica
}

\author{
JOSÉ LUÍS OREIRO \\ LUIZ FERNANDO DE PAULA \\ GUILHERME JONAS COSTA DA SILVA \\ RAFAEL QUEVEDO DO AMARAL*
}

This paper aims at exploring some hypothesis to explain why real interest rate and bank spread are so high. We argue that the interest rate problem and bank spread problem are connected. More precisely, one important cause of bank spread is the high level of BCB interest rate. So, the solution of interest rate problem, so that it can converge to the levels observed in other countries, will help to reduce bank spread, and doing so contributing to the reduction of the capital cost of the Brazilian economy.

Keywords: economic growth; interest rate; Brazilian economy.

JEL Classification: E22; E43; E44; E52.

\section{INTRODUÇÃO}

Nos últimos 25 anos a economia brasileira vem crescendo a uma taxa média de $2,6 \%$ a.a., valor bastante inferior a média observada no período 1947-1980 ( $7,1 \%$ a.a.) e abaixo da taxa média de crescimento obtida por outros "grandes" países emergentes, como, por exemplo, China e Índia ${ }^{1}$. Tendo em vista um crescimento populacional da ordem de $1,5 \%$ a.a o PIB per capita tem crescido nos últi-

\footnotetext{
* Professor do Departamento de Economia da Universidade de Brasília (UnB) e Pesquisador Nível I do CNPq. E-mail: joreiro@unb.br; Professor da Faculdade de Ciências Econômicas da Universidade do Estado do Rio de Janeiro (UERJ) e Pesquisador Nível I do CNPq. E-mail: luizfpaula@terra.com.br; Professor do Instituto de Economia da Universidade Federal de Uberlândia (UFU). E-mail: guilhermejonas@yahoo.com.br; Economista do Departamento Nacional de Produção Mineral. E-mail: quevedoam@yahoo.com.br. Os autores agradecem as sugestões de dois pareceristas anônimos, isentando-os de erros e omissões remanescentes. Submetido: 15/Setembro/2009; Aprovado: 7/Novembro/2011.

${ }^{1}$ No período 1999-2006 as taxas de crescimento médio da China, Índia e Rússia foram, respectivamente, $9,3 \%, 6,8 \%$ e $6,7 \%$, enquanto o Brasil cresceu a 2,8\% (cf. Paula, 2008a, p. 52).
} 
mos anos a uma taxa pouco superior a $1 \%$ a.a. Nesse ritmo levará quase 70 anos para que a renda per capita brasileira dobre de tamanho, igualando-se ao nível de renda per capita prevalecente hoje em dia em países como Portugal e Espanha. Uma das causas dessa situação de semiestagnação é a reduzida formação bruta de capital fixo como proporção do PIB. Conforme Oreiro et al. (2005), para que a economia brasileira possa crescer a uma taxa de $5 \%$ a.a. no longo prazo, sem gerar pressões inflacionárias, a taxa de investimento deveria aumentar para, pelo menos, $25 \%$ do PIB; ou seja, é necessário um aumento de $32 \%$ na formação bruta de capital fixo como proporção do PIB com respeito a média dos últimos 15 anos.

Nesse contexto, a pergunta relevante a ser feita é: como gerar um aumento dessa magnitude na formação bruta de capital fixo como proporção do PIB? Em outros termos, por que razão a taxa de investimento observada na economia brasileira não é suficiente para gerar um crescimento sustentado, não inflacionário, na faixa de $5 \%$ ao ano?

No que se refere aos limites existentes para a expansão da formação bruta de capital fixo, uma hipótese bastante aceita entre os economistas brasileiros é o elevado custo do capital. O Brasil é um país sui generis nesse aspecto à medida que se notabiliza pelo fato de que é detentor da inglória posição de possuir a maior taxa real de juros do mundo (na média do período 1996-2002) e também o maior spread bancário do mundo (Holland, 2006).

O conceito relevante de custo do capital para a avaliação dos projetos de investimento é o custo médio ponderado do capital (weighted average cost of capital - WACC) que consiste numa média entre o custo de oportunidade do capital próprio e o custo do capital de terceiros, ponderados pela participação de cada uma dessas fontes de financiamento no passivo total das empresas.

O custo de oportunidade do capital próprio, por sua vez, consiste na soma entre a taxa de retorno dos investimentos livres de risco e o prêmio de risco que os investidores exigem para investir na empresa. No Brasil, a opção de aplicação financeira com maior liquidez e menor risco de default é a compra de títulos públicos pós-fixados, as chamadas Letras Financeiras do Tesouro (LFT). Uma característica importante das LFTs é que o seu valor nominal é indexado pela taxa Selic fixada pelo BCB nas reuniões do Comitê de Política Monetária (COPOM). Dessa forma, o seu valor de mercado não sofre alterações em virtude de mudanças da taxa nominal de juros, ou seja, a duration desses títulos é igual a zero, o que lhes confere um elevado grau de liquidez ${ }^{2}$. Nesse contexto, a elevada taxa real de juros de curto prazo - ou seja, a taxa real de retorno dos ativos livres de risco - prevalecen-

\footnotetext{
${ }^{2}$ Segundo Carneiro e Wu (2005), a duration pode ser definida como o tempo necessário de retenção de um título no portfólio do investidor para que o mesmo não sofra perdas advindas de uma elevação da taxa de juros. No caso das LFT's, a indexação do preço nominal desses títulos pela Selic faz com que o preço de mercado desses títulos nunca seja reduzido em função de um aumento da taxa de juros; de forma que a sua duration é igual a zero. Assim, o prazo mínimo de retenção do título para se evitar perdas de capital é igual a um dia.
} 
te na economia brasileira estabelece um piso muito alto para o custo de oportunidade do capital próprio.

O segundo elemento do custo do capital é o custo do capital de terceiros. O capital de terceiros pode ser obtido de duas formas: por intermédio da venda de títulos no mercado de capitais ou por intermédio da obtenção de empréstimos junto ao sistema bancário. O tamanho reduzido do mercado de capitais faz com que o financiamento por intermédio da colocação de títulos no mercado de capitais seja pouco relevante, tornando os empréstimos bancários (e do BNDES) a principal fonte de capital de terceiros para as empresas brasileiras. Em função dos elevados spreads cobrados pelo sistema bancário brasileiro, o custo dos empréstimos bancários para as empresas é bastante elevado, aumentando assim o custo do capital de terceiros e contribuindo, portanto, para o elevado custo do capital das empresas observado na economia brasileira.

O presente artigo objetiva avaliar o problema das elevadas taxas de juros no Brasil, apresentando algumas hipóteses e evidências empíricas a respeito do porque a taxa de juros de curto prazo e os spreads bancários são tão elevados. Isso posto, o artigo está dividido em cinco seções, além da introdução. Na segunda seção apresenta-se um modelo teórico simples de determinação da taxa real de juros num contexto de metas inflacionárias. A terceira seção está dedicada a um estudo empírico a respeito de uma das possíveis fontes de perda de eficácia da política monetária no Brasil. A quarta seção apresenta a relação entre o mercado de dívida pública e a política monetária no Brasil. A quinta seção analisa o comportamento do spread bancário no Brasil, enfatizando o papel da taxa básica de juros na explicação do elevado nível do spread bancário brasileiro A última seção sumariza o artigo.

\section{UM MODELO MACROECONÔMICO PARA A DETERMINAÇÃO DA TAXA DE JUROS LIVRE DE RISCO}

Como já assinalado, no Brasil a taxa de juros livre de risco é representada pela taxa Selic, a qual é o instrumento básico de política monetária no atual regime de metas de inflação, implantado em 1999.

Nesta seção apresentaremos um modelo macroeconômico para uma economia que opera sob um regime de metas de inflação, com o intuito de analisar os determinantes da taxa real de juros.

\section{Estrutura do Modelo ${ }^{3}$}

Consideremos uma economia descrita pelo seguinte sistema de equações:

$$
L_{t}=\left(Y_{t}-\bar{Y}\right)^{2}+\beta\left(\pi_{t}-\pi^{*}\right)^{2}
$$

\footnotetext{
${ }^{3}$ A apresentação feita a seguir baseia-se em Carlin e Soskice (2006, p. 153).
} 


$$
\begin{aligned}
& \pi_{t}=\pi_{t-1}+\alpha\left(Y_{t}-\bar{Y}\right)^{2} \\
& Y_{t}=\bar{Y}-\alpha\left(r_{t}-\bar{r}\right)
\end{aligned}
$$

Onde: $Y_{t}$ é o PIB real no período $t, \bar{Y}$ é o produto potencial, $\pi_{t}$ é a taxa de inflação no período $t, \pi^{*}$ é meta de inflação de longo prazo definida pela autoridade monetária ${ }^{4} r_{t}$ é a taxa real de juros no período $t, \bar{r}$ é a taxa natural de juros ${ }^{5} ; \beta$ é uma constante que representa o grau de aversão social a inflação; $\alpha$ é uma constante que representa a sensibilidade da taxa corrente de inflação ao hiato do produto, $a$ é uma constante que representa a sensibilidade da demanda agregada e do nível de produção corrente às divergências entre a taxa real de juros e a taxa natural; e $L_{t}$ é o valor da função perda social.

A equação (1) representa a "função perda social" do policymaker, o qual é suposto escolher os níveis de produto e inflação a cada período do tempo de forma a minimizar a perda social. A equação (2) nada mais é do que uma versão da curva de Phillips expandida pelas expectativas, supondo-se, no entanto, a existência de expectativas adaptativas. Por fim, a equação (3) é uma versão da curva IS para a economia em consideração.

O problema de otimização do policymaker no período $t$ pode, então, ser representado por:

$$
\begin{aligned}
& \operatorname{MinL}_{t}=\left(Y_{t}-\bar{Y}\right)^{2}+\beta\left(\pi_{t}-\pi^{*}\right)^{2} \\
& \text { s.a } \quad \pi_{t}=\pi_{t-1}+\alpha\left(Y_{t}-\bar{Y}\right)
\end{aligned}
$$

A partir da condição de primeira ordem para a solução de (4), chega-se à seguinte equação:

$$
Y_{t}=\bar{Y}-\alpha \beta\left(\pi_{t}-\pi^{*}\right)
$$

A equação (5) define o lócus das combinações entre o nível de produto real no período $t$ e a taxa de inflação no período $t$ para as quais a função perda social é minimizada, ou seja, trata-se das combinações ótimas de produto e inflação por parte do policymaker.

\footnotetext{
${ }^{4}$ No caso brasileiro, o Conselho Monetário Nacional (CMN).

${ }^{5}$ A taxa natural de juros é definida, pela teoria convencional, como o valor da taxa real de juros para o qual o hiato do produto é igual a zero, fazendo com que a inflação permaneça estável ao longo do tempo.
} 
Substituindo (5) em (3), obtemos a seguinte expressão:

$$
r_{t}=\bar{r}+\left(\frac{\alpha \beta}{\alpha}\right)\left[\pi_{t}-\pi^{*}\right]
$$

A expressão (6) nos mostra que a taxa real de juros no período $t$ é determinada por dois elementos. O primeiro elemento é a "taxa natural de juros". Essa taxa é determinada por uma grande miríade de fatores como a taxa de impaciência intertemporal dos consumidores, a elasticidade de substituição intertemporal do consumo, a produtividade marginal do capital, o nível dos gastos do governo, entre outros fatores. O segundo elemento reflete a "dosagem do aperto monetário" que é requerida para fazer com que a inflação corrente convirja com respeito à meta de inflação de longo prazo. Essa dosagem será tão maior quanto: (a) maior for a sensibilidade da inflação ao hiato do produto; (b) maior for o grau de aversão do policymaker aos desvios da inflação com respeito a meta inflacionária de longo prazo e (c) menor for a sensibilidade da demanda agregada às variações da taxa de juros.

Dessa forma, a persistência de um valor elevado da taxas real de juros por longos períodos de tempo, mesmo na ausência de choques exógenos, pode refletir não apenas a existência de uma taxa natural de juros elevada, como também, a ocorrência de ineficiências na execução da política monetária, ineficiências essas que exijam uma "dosagem maior" de aperto monetário para fazer com que a inflação convirja com respeito a meta de longo prazo. A ocorrência de choques exógenos pode aumentar ainda mais a persistência do componente "aperto monetário", fazendo com que o mesmo se torne uma explicação importante para a ocorrência de elevadas taxas reais de juros por longos períodos.

\section{Dinâmica da Taxa Real de Juros}

Para demonstrar a validade das afirmações feitas acima, consideremos uma economia na qual a taxa inicial de inflação é de $8 \%$ a.a. e a meta de inflação de longo prazo é de $4 \%$ a.a. Na trajetória-padrão consideraremos que $\beta=0.5 ; \alpha=1$ e $a=0.5$. A dinâmica da taxa real de juros na trajetória-padrão será, então comparada, com os valores observados em três trajetórias alternativas, a saber: Trajetória I (baixa sensibilidade da demanda agregada às variações da taxa real de juros: $a=0.25$ ), Trajetória II (alto coeficiente de aversão a inflação: $\beta=0.75$ ) e Trajetória III (baixa sensibilidade da demanda agregada + alto coeficiente de aversão a inflação). A taxa natural de juros é suposta igual a $6 \%$ a.a. em todas as trajetórias, de forma que as diferenças observadas na dinâmica da taxa real de juros são devidas unicamente ao componente "aperto monetário".

$\mathrm{Na}$ Figura 1 apresentamos a dinâmica da taxa real de juros na trajetória padrão e nas trajetórias I, II e III. Podemos observar duas coisas nessa Figura. Em primeiro lugar, em todas as três trajetórias, a taxa real de juros converge no longo 
prazo para o valor de equilíbrio dado pela taxa natural de juros. No entanto, a média da taxa real de juros é diferente ao longo das trajetórias em consideração. $\mathrm{Na}$ simulação padrão, a taxa real de juros média ao longo de 30 períodos é de $6,4 \%$ a.a. Na trajetória I, a taxa real de juros média é de $6,6 \%$ a.a., na trajetória III a taxa real média de juros é de $6,8 \%$ a.a., ao passo que na trajetória III a taxa real média de juros é de $7,2 \%$ a.a, ou seja, 80 pontos base superior a taxa de juros prevalecente na simulação-padrão.

Figura 1 : Dinâmica da Taxa Real de Juros sob Diferentes Hipóteses a Respeito da

Sensibilidade-Juros da Demanda Agregada e do Coeficiente de Aversão a Inflação

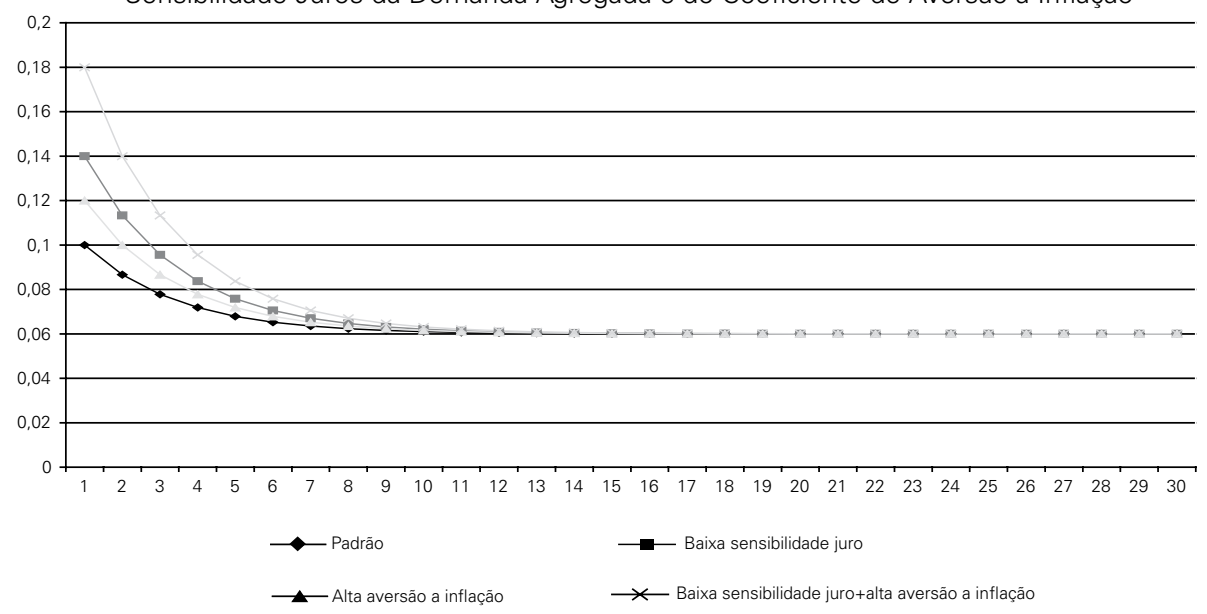

As diferenças existentes entre as taxas médias de juros ao longo das trajetórias simuladas se explicam fundamentalmente pelas diferenças entre as taxas de juros fixadas pelo Banco Central no início do processo de desinflação. Na trajetória-padrão, a desinflação exige uma taxa real de juros inicial de $10 \%$ a.a., na trajetória I a taxa requerida no início do processo sobre para $12 \%$, na trajetória II ela sobe para $14 \%$, ao passo que na trajetória III a taxa requerida é de $18 \%$. Como assinalado, as diferenças nessas taxas resulta da combinação de vários fatores, como sensibilidade da demanda a taxa de juros, coeficiente de aversão a inflação, entre outros.

Esses resultados apontam para a hipótese de que a persistência de um valor elevado para a taxa real de juros de curto prazo no Brasil após a implantação do regime de metas de inflação pode resultar da existência de mecanismos que reduzam a eficácia da política monetária, aumentando assim a taxa real de juros requerida para a convergência da inflação com respeito a meta de longo prazo definida pelas autoridades monetárias.

No modelo teórico exposto acima pudemos identificar, ao menos, duas fontes possíveis dessa ineficácia, a saber: um alto grau de aversão "social” a inflação e uma baixa sensibilidade da demanda agregada às variações da taxa real de juros. 


\section{FONTES DE PERDA DE EFICÁCIA DA POLÍTICA MONETÁRIA NO BRASIL I: A "FUNÇÃO DE REAÇÃO” DO BANCO CENTRAL}

Nesta seção argumentaremos que o Banco Central do Brasil possui, aparentemente, uma "preocupação excessiva" com a taxa de inflação, haja vista que o mesmo utiliza a taxa de juros básica como instrumento para debelar pressões inflacionárias originadas, fundamentalmente, por pressões de custo advindas de variações da taxa nominal de câmbio. A estimação da "função de reação" do Banco Central, ao estabelecer esse padrão de comportamento para a autoridade monetária, aponta para a existência de um elevado grau de aversão a inflação, o que aumenta a taxa de juros requerida para a convergência da inflação a meta de longo prazo, tal como foi visto na seção anterior ${ }^{6}$.

Para demonstrar a validade dessa afirmação, nesta seção, estimaremos a partir da utilização de um modelo VAR — Vetores Auto-Regressivos ${ }^{7}$, a importância do canal do câmbio na função de reação do Banco Central. Para isso procurar-se-á identificar a relação de causalidade entre as principais variáveis relevantes para a determinação da taxa de juros. As variáveis em consideração serão a taxa Selic, a taxa de câmbio, a taxa de utilização da capacidade produtiva na indústria, o índice de preços ao consumidor amplo (IPCA) e as expectativas quanto ao IPCA para 12 meses. As fontes dos dados utilizadas no exercício empírico são i) Taxa de juros Selic do BCB; ii) Taxa de inflação medida a partir da variação mensal do IPCA-E do IBG; iii) Taxa de câmbio - R \$ / US\$ — comercial - compra - média, do BCB; iv) expectativas de inflação do Boletim Focus do BCB; e v) valor mensal do grau de utilização da capacidade produtiva na indústria, da Confederação Nacional da Indústria. Todos os dados foram extraídos do site do Ipeadata.

Dessa forma, estimaremos a dinâmica de determinação da taxa Selic no período de julho de 2001 a abril de 2008, onde se procurará quantificar a importância do câmbio para a política monetária. Optou-se pelo período citado com o objetivo de desconsiderar os dois primeiros anos do regime de metas de inflação e, portanto, analisar o regime em um intervalo de tempo onde o mesmo já se encontrava consideravelmente consolidado como a âncora da política monetária. Além disso, um fator determinante na escolha do período foi a disponibilidade de dados sobre as expectativas de inflação, que só passaram a serem coletadas em 2001.

\footnotetext{
${ }^{6}$ Modenesi (2008) mostra evidências de que a formação da taxa Selic é pautada por uma convenção pró-conservadorismo na condução da política monetária, com um comportamento assimétrico do BCB que eleva mais fortemente a taxa de juros por ocasião de aumento no hiato do produto e/ou no hiato inflacionário, e reduzindo pouco quando diminui tais hiatos.

${ }^{7}$ Para uma discussão da metodologia do modelo VAR, ver, entre outros, Enders (1995).
} 


\section{Estimativa da Dinâmica de Determinação da Taxa Selic (07/2001 a 04/2008)}

A metodologia de Vetores Auto-Regressivos ${ }^{8}$ (VAR), aqui explorada, também é utilizada pelo Banco Central do Brasil para as estimativas a respeito das expectativas para o IPCA e para a produção industrial. Tal modelo pode ser usado como forma de auxiliar nas decisões de política monetária?.

Também foram feitos os seguintes testes: Teste de Causalidade de Granger, decomposição da variância dos erros, Teste de Johansen, teste de endogeneidade das variáveis (VAR Pairwise Granger Causality/Block Exogeneity Wald Tests) e teste de correlação serial dos resíduos. O método de Cointegração de Johansen foi escolhido por ser mais apropriado que o Teste de Engle Granger no caso de um VAR de mais de duas variáveis ${ }^{10}$. Escolheu-se o nível de utilização da capacidade produtiva na indústria como uma proxy da relação produto efetivo/produto potencial.

Primeiramente, foram feitos os testes de estacionaridade das séries, considerando o nível de integração, defasagem da série e as especificações de intercepto e tendência, evitando problemas relacionados a resultados "espúrios”, o que poderia levar a conclusões incorretas. Para tal procedimento utilizou-se o teste de Dickey-Fuller Aumentado (ADF) ${ }^{11}$, que permite incorporar termos defasados extras da variável dependente como forma de eliminar o problema de autocorrelação dos resíduos.

O teste ADF indicou que todas as variáveis em consideração são estacionárias em $1^{\text {a }}$ diferença. Com exceção das expectativas e do câmbio, que apresentaram, respectivamente, uma defasagem de 3 e 2 períodos, as demais variáveis apresentaram 1 lag como a melhor defasagem pelo critério de Schwartz. A melhor defasagem para o modelo como um todo foi de 2 lags $^{12}$, sendo que para tal período o teste LM não mostrou significância na presença de correlação serial dos resíduos, o que valida tal defasagem como a melhor escolha para o lag do modelo. Com o valor da defasagem do sistema determinado estimou-se o Teste de Causalidade de Granger, a decomposição da variância dos erros e a ordem de endogeneidade das variáveis - através do teste VAR Pairwise Granger Causality.

Por fim, com o objetivo de verificar a existência de uma relação de longo pra-

\footnotetext{
${ }^{8} \mathrm{O}$ termo autorregressivo deve-se ao fato de utilizar-se a variável dependente de forma defasada como uma variável independente, enquanto o termo vetor se deve à utilização de um vetor de duas ou mais variáveis (Enders, 1995).

${ }^{9}$ Ver os Relatórios de Inflação do Banco Central do Brasil.

${ }^{10}$ Para uma discussão metodológica sobre os testes citados ver Asterious (2006).

${ }^{11}$ Também foi realizado o teste de Phillips-Perron, que não mostrou divergências com relação ao ADF e, portanto, será desconsiderado para efeito de simplificação da análise.

${ }^{12}$ Utilizou-se como critério o teste de Schwartz. Salienta-se que a utilização de 2 lags não altera os resultados qualitativos.
} 
zo entre as variáveis, foi estimado o Teste de Cointegração de Johansen, onde se identificou a existência de pelo menos dois vetores de cointegração a $5 \%$ de significância. A importância do teste de cointegração advém do fato de que a diferenciação das variáveis leva a perdas nas propriedades de longo prazo (Asterious, 2006) ${ }^{13}$.

A partir dos testes econométricos especificados pode-se fazer algumas inferências sobre a interação dinâmica das variáveis em consideração. Para isso, o diagrama de causalidade entre as variáveis é um instrumento ilustrativo, já que resume as relações significativas do Teste de Causalidade de Granger.

A análise do Teste de Causalidade de Granger explicita os seguintes resultados: A selic é causada pelas variáveis taxa de câmbio, IPCA e expectativas de inflação; o IPCA é causado pelas expectativas de inflação e pela taxa de câmbio; as expectativas, por sua vez, são causadas pela taxa de câmbio e esta última é determinada exogenamente; por fim, o nível de utilização da capacidade é causado pelo IPCA, pelas expectativas e pela selic. A Figura 2 mostra as relações de causalidade entre as variáveis:

Figura 2: Diagrama de causalidade entre as variáveis

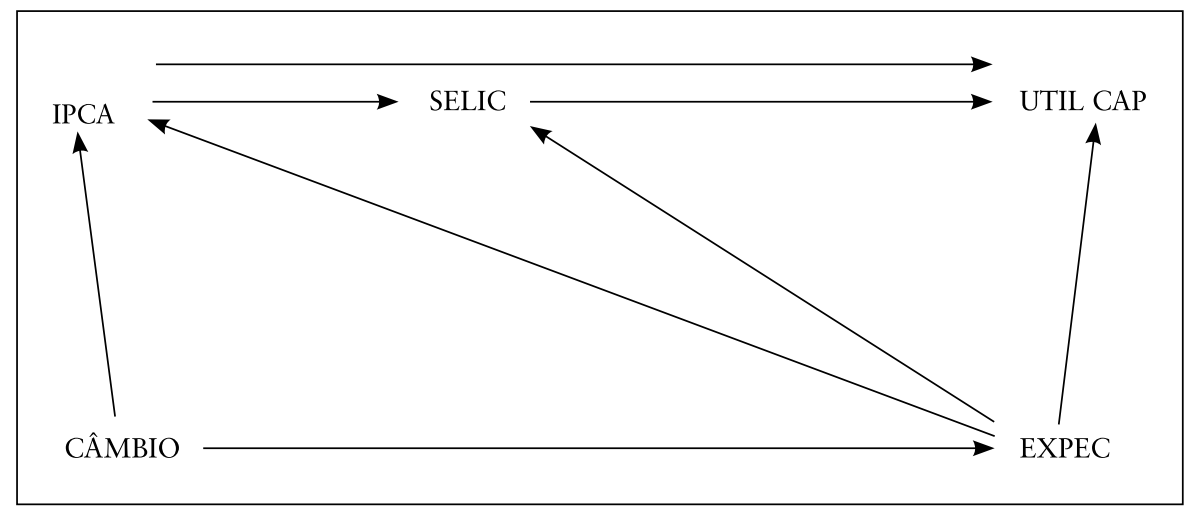

De fato, a taxa de câmbio é uma variável exógena nesse modelo, sendo a principal variável determinante das demais, o que é confirmado pelo teste de en-

13 Quando existe um Vetor de Cointegrante, é comum fazer um VEC. Contudo, segundo Ramaswamy \& Sloek (1997) e Matsumoto (2000), nem sempre esta opção garante os melhores resultados, haja vista que impor um tratamento de cointegração pode levar a estimação tendenciosa e, portanto, enviesar as funções impulso-resposta. Ademais, os autores destacam que, não havendo suficiente fundamento teórico a priori que possa dar respaldo tanto as relações de longo prazo quanto ao modo correto de interpretá-las, o mais aconselhável é não impor nenhuma restrição de correção ao modelo VAR. No caso das variáveis macroeconômicas consideradas no presente trabalho acredita-se não haver razões suficientes que respalde as relações de longo prazo; assim optou-se por tornar as séries estacionárias e estimar um sem impor restrição de correção de erro ao modelo VAR. Assim, a decisão de não empregar o VEC, além dos problemas econométricos supracitados, se deve a uma razão muito simples: em economias emergentes é razoável supor que as ações de política econômicas adotadas causem efeitos em um prazo relativamente curto, de modo que o ganho de informação com a imposição de uma restrição de correção é muito pequeno e o custo relativamente grande. 
dogeneidade das variáveis (VAR Pairwise Granger Causality/Block Exogeneity Wald Tests). Como pode ser constatado do teste de endogeneidade, o nível de utilização da capacidade, a Selic, IPCA e as expectativas, seguem, nessa mesma ordem, a taxa de câmbio em grau crescente de exogeneidade.

Do exposto, pode-se destacar que a taxa de câmbio determina tanto diretamente, como indiretamente, via expectativas e IPCA, a taxa Selic. Ao determinar a taxa Selic por esses dois canais, essa última responde ao IPCA, determinando leve queda no nível de utilização da capacidade. Como pode ser detectado por intermédio da decomposição da variância (Anexo), o impacto da taxa Selic sobre o IPCA e o nível de utilização da capacidade produtiva é consideravelmente modesto. Adotando-se uma defasagem de 12 meses, pode-se afirmar que 11,81\% e $3,69 \%$ das variações da utilização da capacidade e do IPCA, respectivamente, podem ser explicadas pelas variações da Selic. Em outras palavras, variações da taxa Selic têm um impacto reduzido sobre o IPCA, o que pode estar implicando a necessidade de se utilizar "doses elevadas de juros" para conter a demanda agregada e a taxa de inflação.

\section{Interpretação dos Resultados Obtidos}

A elevada participação dos preços administrados no IPCA (cerca de 30\% do índice em 2003-05) e a importância do canal do câmbio na determinação da Selic, seja diretamente, ou seja, via expectativas e IPCA, impõem um comportamento perverso à política monetária. Isso ocorre, em parte, por um certo "efeito amplificador" que a elevada participação dos preços administrados ocasiona sobre os juros. Dito de outra forma, a grande participação dos preços administrados no IPCA faz com que variações cambiais tenham efeitos maiores sobre os preços e, portanto, sobre a taxa de juros, do que se a mesma participação fosse menor.

É notório que um aumento da taxa Selic é capaz de desaquecer a economia e influenciar a demanda dos agentes por bens e serviços, induzindo a redução dos preços quando a inflação é demanda. Entretanto, as evidências encontradas parecem não ratificar tal teoria, haja vista que 12 meses após os choques na taxa básica de juros, a inflação se alterou apenas em 3,7\% da inflação observada. Ademais, os principais determinantes da inflação nesta análise foram: a taxa de câmbio e a expectativa de inflação, com $30 \%$ e $35 \%$, respectivamente. Esta pode ser uma evidência de que a inflação no Brasil não é necessariamente de demanda pela análise realizada no período em consideração. Nos períodos subsequentes (12 meses após os choques na Selic), a função impulso-resposta e a decomposição da variância mostraram que estes percentuais se estabilizaram nos patamares supracitados, como esperado, já que as ações de política monetária adotadas no Brasil afetam as variáveis macroeconômicas, em geral, e a inflação, em particular, por um período relativamente curto. Em função disso, os resultados podem ser interpretados como contrários a lógica tradicional da Curva de Phillips (elevações da taxa de nominal e real de juros causam uma redução do nível de produto, forçando assim uma re- 
dução da taxa de inflação), o que pode implicar que os custos da atual política de combate a inflação são maiores que os benefícios desta.

Apesar de a política monetária ter um caráter relativamente passivo dentro do sistema, ou seja, responder à taxa de inflação, o grau com que tal causalidade ocorre é extremamente modesto. Sendo assim, elevações da taxa Selic, ao não explicarem variação significativa da taxa de inflação, mostram que essa variável está operando com considerável perda de eficácia. Pode-se inferir que tal anomalia seja derivada tanto da participação dos preços administrados, que não respondem a elevações da Selic, como da perversidade do mercado de dívida pública no Brasil. Esse último fator é explicitado no baixo efeito riqueza da política monetária, devido a excessiva participação de títulos pós-fixados, mais especificamente LFTs, na composição da DMFi, como será analisado na próxima seção.

Os resultados encontrados parecem indicar a necessidade de mudança em dois fronts. Primeiro, faz-se necessário a adoção de alguma medida para reduzir a volatilidade cambial na economia brasileira. Em segundo lugar, é preciso diminuir a participação dos preços administrados, o que passa necessariamente por uma revisão de contratos e desindexação dos preços monitorados ao IGPM e IGP-DI, como no caso de telefonia fixa e energia elétrica ${ }^{14}$.

\section{FONTES DE PERDA DE EFICÁCIA DA POLÍTICA MONETÁRIA NO BRASIL II: RELAÇÃO ENTRE O MERCADO DE DÍVIDA PÚBLICA E A POLÍTICA MONETÁRIA}

A estrutura da dívida pública brasileira e, por sua vez, o mercado de títulos públicos, explicitam outra possível fonte de perda de eficácia da política monetária. Pode-se constatar que essa não é a única, mas a forma como ocorre a ligação entre o mercado de títulos públicos e a política monetária caracterizam uma fonte peculiar de perda de eficácia desta última. O problema não advém da necessidade da política monetária responder a uma ou mais variáveis, mas sim do fato de que tal resposta tem seus efeitos enfraquecidos, ou até mesmo distorcidos, pela característica do mercado de títulos da dívida ${ }^{15}$.

O fator determinante desse problema é a grande participação de títulos pós-fixados, mais especificamente as LFTs, na composição da dívida líquida do setor

\footnotetext{
${ }^{14}$ Retornamos a essas questões na conclusão.

${ }^{15}$ Martins (2009, cap. 1) realiza um exercício econométrico em que utiliza a posição financeira dos bancos brasileiros em títulos públicos indexados à taxa de juros (LFTs) para testar o canal dos empréstimos bancários para a política de juros no Brasil, e os resultados encontrados apontam para a potencial relevância deste canal de transmissão da política monetária na economia brasileira, mas conclui que a expressiva participação dos títulos indexados às taxas de juros na carteira dos bancos contribuem para tornar este canal menos evidente. Deve-se assinalar que a importância dos títulos indexados a Selic têm diminuído no período recente, com prováveis efeitos positivos sobre a melhoria da eficácia dos mecanismos de transmissão da política monetária no Brasil.
} 
público, doravante denominada DLSP. A participação desses títulos na DLSP chegou a atingir $54,3 \%$ em outubro de 2005 , alcançando, em novembro de 2006 , $38,7 \%$, caindo para $28,7 \%$ em março de $2008^{16}$.

A mudança de denominação de LBC para LFT surgiu com a constituição de 1988, que proibiu o financiamento direto e indireto do Banco Central à União, viabilizado anteriormente pelas contas movimento e suprimentos. Com a nova Constituição Federal criou-se a conta única da União no Banco Central, permitindo que esse último utilizasse os títulos do Tesouro como instrumentos de política monetária.

A própria introdução das LBC durante o Plano Cruzado é uma confirmação da necessidade de se conciliar as ações de política monetária com a administração da dívida. Nesse período, não sendo possível elevar a taxa de juros e manter o estoque de títulos pré-fixados sem o desenrolar de uma crise sistêmica, ficou o Banco Central "forçado" a trocar os títulos com risco de perda de capital por Letras do Banco Central, que têm a característica de não possuírem risco de taxa de juros. Esse fato parece ter se consumado desde então, ressurgindo episódios da mesma natureza, por exemplo, durante a crise asiática em 1997 e nas crises de marcação a mercado e pré-eleitoral em 2002.

Ambos os eventos atuaram como fatores limitadores do processo de alongamento do prazo médio da dívida, que vinha ocorrendo com a introdução de títulos pré-fixados e pós-fixados de maior prazo. Dessa forma, o Banco Central e o Tesouro Nacional frequentemente acabam se rendendo à necessidade de recomprar títulos do mercado com o objetivo de preservar a liquidez dos mesmos e garantir a rolagem da dívida pública (Ferreira et al., 2004).

Dessa forma, retira-se parte do efeito riqueza da política monetária. Esse efeito opera da seguinte forma: mudanças na política monetária, ou seja, no valor da taxa nominal de juros, afetam o valor de mercado dos ativos o que, por sua vez, afeta os gastos dos consumidores com serviços e bens de consumo. Considerando que o efeito riqueza, ou seja, o impacto que mudanças nos juros exercem sobre a riqueza financeira dos agentes e, portanto, sobre sua possibilidade de consumo e investimento, é um dos canais de transmissão da política monetária, dois problemas tornam-se evidentes.

Primeiro, a venda de títulos com cláusula de recompra elimina ao menos parte do efeito riqueza da política monetária. Segundo, a magnitude da participação das LFTs na dívida mobiliária, dada a característica peculiar de formação do preço desse título, faz, mais uma vez, com que o efeito riqueza da política monetária seja inexpressivo.

Os dois fatores citados no parágrafo anterior atuam como um limitador na capacidade de se conduzir uma política monetária com maior eficácia. Ao se retirar o efeito riqueza como um canal de transmissão da política monetária, ocorre uma redução da sensibilidade da demanda agregada as variações da taxa de juros. Isso

${ }^{16}$ Cf. dados do BCB-DEPEC. 
porque elevações da taxa nominal de juros deixam de ter efeito sobre o valor de mercado dos títulos públicos ${ }^{17}$ (pelo menos sobre a parcela da dívida indexada a taxa de juros), acarretando apenas uma elevação do fluxo de rendimentos apropriados pelos detentores desses títulos. Nesse contexto, uma elevação da taxa de juros terá impacto reduzido sobre as decisões de consumo e de investimento dos agentes econômicos. Ainda, dependendo da participação das LFTs no estoque da dívida e da disponibilidade da autoridade monetária em recomprar títulos pré-fixados, ou trocá-los por LFTs em momentos de crise, o efeito de mudanças na taxa de juros pode ser o inverso do esperado. Isso pode ocorrer pelos simples fato de que ao se enfraquecer o efeito riqueza, elevações da taxa de juros atuarão somente no sentido de valorização dos ativos, dada a característica de duração zero das $\mathrm{LFTs}^{18}$.

Concluindo, o Brasil é o único país no mundo onde o banco central determina diretamente as taxas de juros que remuneram a dívida pública e essas são usadas também como meta operacional de política monetária, determinando o custo das reservas bancárias. Essa situação anômala constitui uma herança da era da alta inflação que ainda permanece intacta, como observado anteriormente. De fato, como cerca de $30 \%$ a $40 \%$ dos títulos federais tem sido indexados à taxa overnight (Selic) e eles são utilizados pelos bancos na composição dos fundos de renda fixa, logo qualquer aumento nas taxas de juros resulta em um aumento imediato do estoque total da dívida pública. Ocorre que, sob estas condições, uma elevação da taxa de juros por parte do BCB, como ocorreu a partir de meados de 2004, é seguida, ceteris paribus, por um aumento nas condições de liquidez da economia. Isso pode, também, causar um maior nível de gastos de consumo por parte das empresas e das famílias, visto que o aumento da remuneração dos fundos de renda fixa gera um efeito de riqueza positivo sobre o consumo. Esse aumento nos gastos, por sua vez, sobrepõe-se ao impacto negativo no consumo que resulta de maiores taxas de juros (Nakano, 2005).

Há duas consequências deste modus operandi da política monetária brasileira. Primeiro, de modo a ter impacto sobre a demanda, o BCB precisa elevar a taxa de juros numa magnitude suficientemente grande para que os bancos sejam forçados a racionar o crédito devido ao aumento do risco de inadimplência. Segundo, o aumento das taxas de juros, em um contexto de arbitragem entre as taxas domésticas e externas e de abundância na liquidez internacional, causa uma apreciação cambial. Isso funciona como um choque positivo no lado da oferta da economia, pois reduz os custos das matérias-primas importadas e dos preços dos bens comer-

\footnotetext{
${ }^{17}$ No caso de títulos públicos não indexados a taxa básica de juros — por exemplo, uma perpetuidade — uma elevação da taxa de juros irá acarretar uma redução imediata do valor de mercado desse título, impondo uma perda de capital ao seu detentor. Essa perda de capital deverá atuar no sentido de reduzir as possibilidades de consumo e/ou de investimento desse agente, contribuindo assim para a redução da demanda agregada.

${ }^{18}$ Mesmo que o efeito riqueza não seja eliminado por completo, o que parece ser o caso, a redução do mesmo pode implicar que a valorização da riqueza derivada do aumento dos juros supere a perda de capital.
} 
cializáveis no mercado doméstico. Consequentemente, é principalmente através do efeito transmissor da taxa de câmbio que a política monetária tem tido efeito sobre a inflação no Brasil.

\section{SPREAD BANCÁRIO E O CUSTO DO CAPITAL DE TERCEIROS: EVIDÊNCIAS EMPÍRICAS PARA O CASO BRASILEIRO}

Nas seções anteriores vimos que a taxa de juros livre de risco, um dos componentes do WACC, é muito elevada no Brasil em função da existência de elementos que reduzem o grau de eficácia da política monetária, aumentando assim a taxa de juros requerida para garantir a convergência da taxa de inflação com respeito à meta inflacionária definida pelas autoridades monetárias.

Nesta seção iremos focar nossa análise sobre os determinantes do spread bancário no Brasil, haja vista que a principal fonte de financiamento externo para os projetos de investimento é o setor bancário. Nosso foco será tão somente o spread cobrado sobre as operações de crédito dos bancos comerciais, deixando de lado as operações de crédito realizadas por intermédio do BNDES.

A hipótese a ser testada é que os fatores macroeconômicos, notadamente a evolução da taxa básica de juros, possuem um papel importante na explicação do elevado nível do spread bancário no Brasil. Dessa forma, o custo do capital de terceiros é alto no Brasil porque o custo do capital próprio também é elevado. Em outras palavras, o elevado custo do capital próprio seria, assim, a causa causans do elevado custo do capital observado na economia brasileira.

\section{Panorama Geral do Spread Bancário no Brasil}

O spread nas operações bancárias é definido como a diferença entre a taxa de aplicação nas operações de empréstimo e a taxa de captação de recursos pelas instituições financeiras. O comportamento do spread no Brasil apresentou uma nítida tendência de queda até início do ano 2000, mas apresenta algumas peculiaridades. O spread médio cobrado pelos bancos brasileiros alcançou um valor máximo de $150 \%$ ao ano no início de 1995 , em função da política monetária fortemente contracionista adotada pelo BCB no período após a implementação do Plano Real. O spread bancário médio foi sendo reduzido de forma significativa no decorrer de 1996, em função de um relaxamento das medidas de arrocho monetário e uma diminuição da desconfiança dos agentes em relação ao processo de contágio da crise mexicana, até atingir o patamar de aproximadamente $40 \%$ ao ano no início de 2000. Cabe ressaltar que ele manteve-se nesses patamares - ainda elevadíssimos - desde então, comportamento que parece estar sinalizando uma rigidez para baixo do spread bancário no Brasil.

Uma primeira hipótese explicativa para o porquê dos elevados spreads praticados no Brasil seria o poder de mercado dos bancos, evidenciado pelo aumento do grau de concentração do setor bancário no período recente. Com efeito, alguns 
estudos recentes sobre o setor bancário brasileiro - como, por exemplo, Belaisch (2003) - mostram que a estrutura de mercado prevalecente nesse setor é essencialmente não competitiva. Nesse contexto, os bancos teriam poucos incentivos para aumentar a sua eficiência operacional, operando com spreads elevados quer como forma de gerar receita suficiente para cobrir os seus custos elevados, quer como resultado da sua capacidade de precificar os seus serviços num patamar bastante superior ao custo marginal de produção dos serviços bancários.

A literatura brasileira que trata dos determinantes do spread bancário não tem sido conclusiva a respeito desse assunto. Os estudos realizados apresentam evidências que a estrutura de mercado do setor bancário brasileira é imperfeita, mas não pode ser caracterizada por nenhuma estrutura de mercado extrema, ou seja, nem pelo modelo de concorrência perfeita nem pelo modelo de cartel (Nakane, 2002).

No Brasil, um dos estudos pioneiros sobre os determinantes do spread bancário no Brasil foi feito por Aronovich (1994), que verificou, através de uma regressão por mínimos quadrados em dois estágios, os efeitos da inflação e do nível de atividade sobre o spread para a economia brasileira entre o primeiro trimestre de 1986 e o quarto trimestre de 1992 . Os resultados encontrados indicam que a inflação tende a ampliar a diferença entre as taxas de juros de empréstimo e de captação, ou seja, o spread. O autor sugere como causas desse fenômeno a possibilidade de uma redistribuição entre as operações do ativo, ou ainda, a incorporação ao mark-up do prêmio de risco envolvido no crédito. Nesse contexto, a inflação teria um efeito negativo sobre o nível de atividade ao induzir um aumento das taxas de juros para empréstimos bancários. Por outro lado, os testes estatísticos sugerem que um aumento da utilização de capacidade produtiva reduziria o spread, indicando assim um efeito pró-cíclico.

Neste mesmo sentido, Afanasieff et al. (2002), utilizando a abordagem de dois passos de Ho \& Saunders (1981), investigaram a relevância dos fatores macro e microeconômicos para explicar o comportamento do spread no país, e concluíram que as variáveis macroeconômicas - como a taxa básica de juros e o crescimento do produto - são os fatores mais relevantes para explicar tal comportamento ${ }^{19}$. Esse resultado, contudo, não é surpreendente, considerando que outros estudos internacionais apresentam evidências de que a incerteza do ambiente econômico que envolve os bancos parece ser uma importante causa dos spreads bancários (Saunders \& Schumacher, 2000; Brock \& Suarez, 2000).

\section{2 - Determinantes Macroeconômicos do Spread Bancário no Brasil (07/1994 a 12/2007)}

Com intuito de identificar os principais determinantes macroeconômicos do spread bancário no Brasil, estimamos um Vetor Auto-Regressivo (doravante VAR) para o período de julho de 1994 a dezembro de 2007, no qual uma variável é de-

\footnotetext{
${ }^{19}$ Ver, também, Silva et al. (2007).
} 
finida como sendo função de seus próprios valores defasados e de defasagens das demais variáveis consideradas na análise. A escolha dessas variáveis baseou-se, em larga medida, nos resultados obtidos por Afanasieff et al. (2002), no qual se conclui que as variáveis macroeconômicas são mais relevantes na determinação do spread do que as variáveis microeconômicas.

Isso posto, o objetivo desta subseção é encontrar os determinantes macroeconômicos do spread bancário no Brasil. A hipótese a ser testada é que o spread é determinado, entre outras variáveis, pela produção industrial, pela taxa de inflação, pela taxa de câmbio e pela taxa básica de juros (efeito da taxa média de juros). As variáveis selecionadas para o exercício empírico foram: i) Spread bancário, segundo o BCB (definido como a série 3955 - spread médio das operações de crédito com recursos livres "prefixado" - total geral); ii) Produto Industrial Brasileiro (PIB) do IBGE utilizado como uma proxy para o nível de atividade econômica (definido como a tabela 2295 do IBGE: Produção Física Industrial por tipo de índice e seções e atividades industriais); iii) Taxa de juros Selic do BCB (definida como a série 4189: taxa de juros Selic acumulada no mês anualizada); iv) Taxa de inflação medida a partir da variação mensal do IPCA do IBGE (definida como a série 433 do BCB: Índice Nacional de Preços ao Consumidor-Amplo); v) Taxa de câmbio - R \$ / US\$ - comercial - compra - média (extraída do Ipeadata).

Para a aplicação empírica, verificou-se através do teste de Dickey-Fuller Aumentado (ADF), da análise gráfica e do diagrama da função de autocorrelação, a hipótese de estacionariedade das séries estudadas. Os testes aplicados mostraram que nenhuma das variáveis consideradas foi estacionária em nível ${ }^{20}$. Assim, após verificar a ordem de integração das variáveis, realizou-se o teste de cointegração de Johansen, com tendência determinística linear nos dados, com intercepto e sem tendência na equação de cointegração ${ }^{21}$. Apesar de existir uma relação de longo prazo entre as variáveis, alguns desequilíbrios de curto prazo podem ocorrer. Nesse caso, deve-se estimar um modelo com correção de erros. As estatísticas traço $\left(L R_{\text {trace }}\right)$ e máximo autovalor $\left(L R_{\max }\right)$ apontaram a presença de um vetor de cointegração, indicando a necessidade de incorporar um vetor de correção de erro. Para desenvolver um modelo bem especificado é necessária, entre outras coisas, a escolha adequada do número de defasagens para fazer as estimações. Para tanto, toma-se como base o Critério de Informação de Akaike (AIC) e Hannan-Quinn (HQ). O resultado observado sinalizou que o número de defasagens a incluir no VAR é igual a um².

\footnotetext{
${ }^{20}$ Apesar do teste ADF ter sinalizado que as séries IPCA, SPREAD e JUROS são estacionários, a análise gráfica e principalmente do correlograma apontaram na direção oposta, por isso não foram consideradas estacionárias em nível.

${ }^{21}$ Essa especificação parece ser a mais apropriada para as séries macroeconômicas analisadas nesse trabalho.

${ }^{22}$ A análise do número de defasagens se baseou nos Critérios de AIC, de HQ e na análise da ausência de correlação serial dos resíduos.
} 
Com base em Mendonça (2005), e considerando que os erros são ortogonalizados pela decomposição de Cholesky para a estimação do modelo, isso implica que o ordenamento das variáveis torna-se relevante para a análise da função impulso-resposta e da decomposição da variância. Para tanto, utilizou-se o teste de precedência temporal de Granger (1969). De acordo com esse critério, a ordenação adequada é a seguinte: DIPCA, DCÂMBIO, DPIB, DJUROS e DSPREAD. Assim, a taxa de variação do spread bancário (variável de interesse nesse estudo) é a mais endógena, respondendo contemporaneamente as variações da taxa de inflação, da taxa de câmbio, do produto e da taxa de juros.

Para analisar os resultados do modelo VAR (restrito ou irrestrito) é comum fazê-lo por meio da função de impulso resposta e da decomposição da variância. Dada a frequência mensal dos dados utiliza-se para as análises um período de 12 meses após a ocorrência dos choques. A função de impulso resposta é utilizada para fazer uma análise da sensibilidade de determinadas variáveis a certos choques, sendo útil principalmente para conhecer o tempo, a direção, o padrão de reação das respostas aos impulsos (choque) de um desvio-padrão sobre os valores contemporâneos e futuros das variáveis endógenas do sistema.

Isso posto, a resposta do sistema aos choques estão apresentadas na Figura 6. O primeiro gráfico mostra que o efeito de um choque no crescimento da inflação sobre o crescimento do spread bancário tende a provocar uma elevação persistente deste último. Este resultado está em consonância com o resultado obtido por Aronovich (1994), o qual já havia mostrado que elevações da taxa de inflação estão associadas com um aumento do mark-up do setor bancário. O gráfico seguinte apresenta o efeito de um choque no crescimento do câmbio sobre o crescimento spread bancário, que também foi positivo ainda que pouco significativo.

Antes de explicar o resultado do último gráfico da primeira linha é interessante destacar que o impacto negativo do PIB sobre o spread bancário pode ser atribuído ao "efeito inadimplência", no sentido de que um maior (menor) crescimento do produto e da renda nacional resulta em uma diminuição (aumento) na inadimplência dos empréstimos bancários (e no risco do crédito) que tende a acarretar uma redução (aumento) no spread. Já o impacto positivo sobre o crescimento do spread se deve provavelmente ao efeito "poder de mercado" dos bancos. Nesse último caso, os bancos, em uma conjuntura de aumento na demanda por crédito, podem responder a este estímulo elevando a taxa de empréstimos e mantendo a taxa de depósitos inalterada. Dado isso, observemos no primeiro gráfico da segunda linha que um choque na taxa de crescimento do PIB causa um efeito negativo sobre a taxa de crescimento do spread bancário, sinalizando que o efeito inadimplência é relativamente mais forte no país. O segundo gráfico da segunda linha mostra o impacto que um choque positivo do spread bancário tende a provocar na própria variável. Podemos observar que o spread, tal como outras variáveis econômicas, possuem um forte componente inercial, o que fica demonstrado pelo fato de que choques sobre essa variável (ou na sua taxa de crescimento) no tempo $t$ têm efeito sobre os valores dessa variável em períodos subsequentes. 
Figura 3: Função resposta do crescimento do spread a um impulso no crescimento das variáveis macroeconômicas

Response to Cholesky One S. D. Innovations
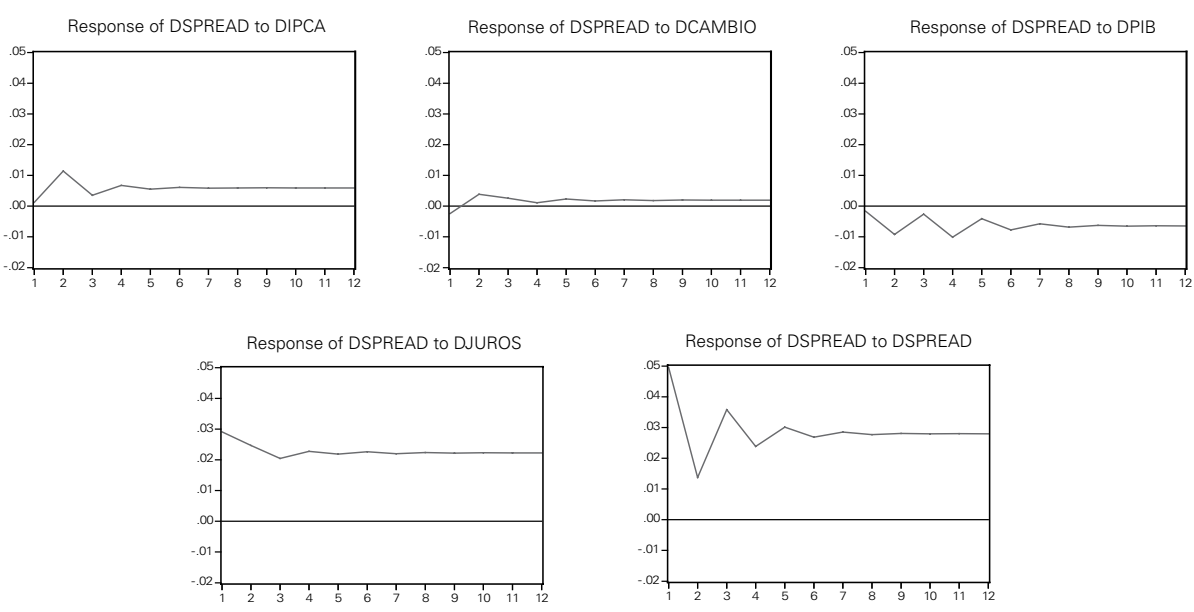

No primeiro gráfico da $2^{a}$ linha encontra-se o efeito de um choque no crescimento da taxa média de juros sobre o crescimento do spread que foi positivo e pode ser considerado o choque que teve o maior impacto sobre o crescimento do spread bancário. Este resultado confirma a hipótese de preferência pela liquidez dos bancos (Paula \& Alves Jr., 2003), segundo a qual os bancos no Brasil - em face da existência de uma aplicação livre de risco que combina liquidez e rentabilidade, como no caso de títulos públicos indexados - passam a incorporar um elevado prêmio de liquidez nas operações de concessão de empréstimos. Acrescente-se que elevações da taxa de juros básica podem ocasionar uma maior variabilidade no nível da produção real e na lucratividade das firmas, elevando o risco de crédito, resultando assim em taxas de empréstimos e spreads maiores.

A Tabela 1 apresenta a decomposição da variância, que tem por objetivo mostrar a importância de uma determinada variável quando se observa o erro de previsão de uma outra variável. Os resultados foram obtidos a partir de uma simulação de Monte Carlo com mil repetições. Note que os crescimentos na taxa de inflação e no PIB responderam por aproximadamente $3 \%$ da variância do crescimento do spread bancário. Os resultados mostraram que o crescimento da taxa de juros é a variável mais relevante, pois tem uma importância grande sobre a variância do crescimento do spread bancário, ou seja, cerca de $35 \%$. No tocante a importância do crescimento do spread bancário na explicação dele mesmo, constatou-se que representa aproximadamente $59 \%$, confirmando a hipótese de haver um forte componente inercial. A importância relativa da taxa de câmbio sobre o crescimento do spread é desprezível. 
Tabela 1: Decomposição da Variância (\%) — Taxa de Variação do Spread Bancário

\begin{tabular}{|l|l|l|l|l|l|}
\hline \multicolumn{1}{|c|}{ Período } & \multicolumn{1}{|c|}{ DIPCA } & \multicolumn{1}{|c|}{ DCAMBIO } & \multicolumn{1}{|c|}{ DPIB } & \multicolumn{1}{c|}{ DJUROS } & \multicolumn{1}{c|}{ DSPREAD } \\
\hline 1 & 0.044337 & 0.175264 & 0.079831 & 25.62277 & 74.07780 \\
\hline 2 & 3.039670 & 0.477410 & 2.029726 & 33.61153 & 60.84166 \\
\hline 3 & 2.379948 & 0.450277 & 1.565313 & 30.91062 & 64.69384 \\
\hline 4 & 2.595357 & 0.391002 & 2.707208 & 32.76118 & 61.54526 \\
\hline 5 & 2.517387 & 0.389100 & 2.450433 & 32.84930 & 61.79378 \\
\hline 6 & 2.556332 & 0.366708 & 2.716666 & 33.57998 & 60.78031 \\
\hline 7 & 2.551644 & 0.360777 & 2.680743 & 33.79313 & 60.61371 \\
\hline 8 & 2.554471 & 0.348965 & 2.760214 & 34.13037 & 60.20598 \\
\hline 9 & 2.559078 & 0.343179 & 2.770633 & 34.32826 & 59.99885 \\
\hline 10 & 2.559550 & 0.336582 & 2.803285 & 34.52641 & 59.77418 \\
\hline 11 & 2.562613 & 0.331900 & 2.820173 & 34.67588 & 59.60944 \\
\hline 12 & 2.563361 & 0.327501 & 2.838948 & 34.81098 & 59.45921 \\
\hline
\end{tabular}

Fonte: Elaboração própria a partir da saída do Eviews 5.

Nota: Ordem Cholesky DIPCA, DCÂMBIO, DPIB, DJUROS e DSPREAD.

Em suma, as evidências recentes parecem indicar que a taxa básica de juros é a variável mais relevante na explicação do crescimento do spread bancário no país. Adicionalmente, constatou-se que a taxa de inflação tem um efeito positivo sobre o crescimento do spread bancário, resultado que está associado com um aumento do mark-up do setor bancário, mas atualmente não pode ser considerado um dos principais determinantes do elevado spread bancário no Brasil. Ainda que as evidências não sejam concretas da relevância do efeito do crescimento da produção industrial na determinação do spread bancário cobrado no país, pode-se afirmar que o "efeito inadimplência" sobressai-se ao "efeito poder de mercado". No que tange o crescimento da taxa de câmbio, o efeito é praticamente nulo. Por fim, deve-se destacar a existência de um forte componente inercial na determinação do spread bancário no Brasil. Isso pode significar que o spread bancário médio prevalecente na economia brasileira deverá permanecer em patamares ainda elevados por um longo tempo após uma redução significativa da taxa básica de juros.

\section{CONCLUSÃO}

Ao longo deste artigo procuramos avaliar as causas das elevadas taxas de juros prevalecentes na economia brasileira. Para tanto, analisamos os determinantes do spread bancário e da taxa de juros de curto prazo. No que se refere aos determinantes do spread bancário, nossa análise mostrou a importância dos fatores macroeconômicos, em particular, a taxa básica de juros. Dessa forma, podemos concluir que o problema do elevado spread bancário é um reflexo direto do problema das elevadas taxas de juros observadas na economia brasileira. Além disso, foi detectado um importante componente inercial da formação do spread bancário 
brasileiro, de forma que uma redução maior e duradoura da taxa básica de juros por parte do Banco Central só terá um impacto significativo sobre o spread após um intervalo de tempo considerável.

No que se refere ao "problema dos juros", nossa análise aponta para uma explicação baseada na perda de eficácia da política monetária, causada tanto pela dinâmica de determinação da taxa Selic como pela composição da DMFi. Essa perda de eficácia atua no sentido de aumentar o valor da taxa real de juros que é requerida para a convergência da taxa de inflação com respeito a meta inflacionária de longo prazo.

A dinâmica da função de reação do Banco Central do Brasil indica que a taxa Selic reage às variações da taxa nominal de câmbio, as quais são o principal determinante da variação do IPCA. Dessa forma, o BCB termina por elevar a taxa de juros básica para combater pressões inflacionárias que não advém necessariamente do lado da demanda da economia, mas que são causadas frequentemente pelas pressões de custo oriundas dos efeitos da desvalorização cambial sobre o custo de produção das firmas. Como a inflação brasileira é predominantemente uma inflação de custos, a política monetária só pode ter impacto sobre a taxa de inflação por intermédio de aumentos significativos da taxa básica de juros.

No que se refere a composição da DMFi, ainda fortemente indexada por LFTs, pode-se constatar que a característica desse títulos, no que se refere à formação de seu preço, dilui o efeito riqueza da política monetária. Além de eliminar um dos canais de transmissão da política monetária, as LFTs levam à concentração da riqueza financeira no curto prazo, inibindo a ampliação do mercado de capitais e o alongamento e aumento da duração da dívida pública. Portanto, não só dificultam a queda dos juros como atuam como um custo de oportunidade para uma realocação de recursos que seja favorável à retomada do crescimento econômico.

Nesse contexto, ao mesmo tempo em que a participação dos preços administrados aumenta a frequência de ajustes necessários na política monetária e as LFTs aumentam a magnitude do ajuste necessário, a concentração da riqueza no overnight diminui o crédito na economia e inibe o crescimento do mercado de capitais. Desse modo, o crescimento econômico é inibido pela manutenção de uma política monetária restritiva e de condições não favoráveis à criação de um ambiente propício ao investimento na atividade produtiva.

A título de sugestão, propomos que a solução do problema das elevadas taxas de juros no Brasil pode ser enfrentada com atuação em três fronts. Em primeiro lugar, podem ser adotadas medidas que visem à redução da volatilidade cambial observada na economia brasileira, de maneira a suavizar os movimentos da taxa nominal de câmbio ao longo do tempo. Para tanto, pode ser necessária a adoção de medidas de controles de capitais na linha sugerida por Paula et al. (2003), em conjunto com uma política de acumulação de reservas. Em segundo lugar, deve-se proceder a uma desindexação generalizada dos contratos dos preços administrados (eletricidade telefonia, etc.) de maneira a impedir que uma eventual desvalorização da taxa nominal de câmbio seja repassada para os preços administrados e, por intermédio deles, para a taxa de inflação medida pelo IPCA. Por fim, faz-se neces- 
sária a eliminação das LFTs como indexador da DMFi, através de uma política ativa de administração da dívida pública, uma condição necessária para a diminuição do custo de administração da dívida no médio e longo prazo e para o aumento da eficácia da política monetária e, consequentemente, para uma queda da taxa de juros no país.

\section{REFERÊNCIAS BIBLIOGRÁFICAS}

AFANASIEFF, T.S., LHACER, P.M.; NAKANE, M.I. (2002). "The determinants of bank interest spread in Brazil". Money Affairs, XV(2): 183-20.

ARIDA, P. (2006). “As Letras Financeiras do Tesouro em seu vigésimo aniversário”. In: BACHA, E.L.; OLIVEIRA, L.C. (org.). Mercado de Capitais e Dívida Pública. Rio de Janeiro: Contra Capa.

ARONOVICH, S. (1994). "Uma nota sobre os efeitos da inflação e do nível de atividade sobre o spread bancário". Revista Brasileira de Economia, 48(1): 125-140.

ASTERIOUS, D. (2006). Applied Econometrics: a modern approach using eviews and microfit. New York, Palgrave Mcmillan, 2006.

BACHA, E.L.; OLIVEIRA, L.C. (2006). Mercado de Capitais e Dívida Pública. Rio de Janeiro: Contra Capa.

BANCO CENTRAL DO BRASIL — BCB (2007). http://www.bcb.gov.br. Acesso em: 11 de novembro de 2008.

BELAISCH, A. (2003). “Do Brazilian banks compete?”. IMF Working Paper WP/03/113.

BROCK, P. L.; SUAREZ, L.R. (2001). "Understanding the behavior of bank spreads in Latin America”. Journal of Development Economics, 63: 113-134.

CARNEIRO, D.D. (2006). “Letras Financeiras do Tesouro e normalidade financeira: haverá um 'peso problem'?” In: BACHA, E.L.; OLIVEIRA, L.C. (org.). Mercado de Capitais e Dívida Pública, op.cit.

CARNEIRO, D.D.; Wu, T. (2005). “A qualidade da dívida pública brasileira”. Casa das Garças, Texto para Discussão n. 9, Novembro.

ENDERS, W. (1995). Applied Econometric Times Series. New York: John Wiley \& Sons, Inc., 2a Edição.

FERREIRA, C.K.; ROBOTTON, M.F.; DUPITA, A.B. (2004) "Política monetária e alongamento da dívida pública: uma proposta de discussão". Texto para Discussão, n. 09/2004, PUC-SP.

GRANGER, C.W.J. (1969). "Investigating causal relations by econometric models and cross-spectral methods". Econometrica, vol. 37, pp. 424-438.

GREENE, W. H (2005). Econometric Analysis. Pearson Education: Delhi.

HO, T.S.Y.; SAUNDERS, A. (1981). "The determinants of bank interest margins: theory and empirical evidence". Journal of Financial and Quantitative Analysis, 16: 581-600.

HOLLAND, M. (2006). "Por que as taxas de juros reais são tão elevadas no Brasil”. Economia \& Tecnologia, 4(2): 27-423. CEPEC/UFPR.

IPEADATA: Banco de dados. Disponível em:<http://www.ipea.gov.br/SobreIpea/ipeadata >. Acesso em: junho 2009.

LUDVIGSON, S.; STEINDEL, C.; LETTAU, M. (2002). "Monetary Policy Transmission through the consumption-wealth channel”. Economic Policy Review, May, 117-133.

MARTINS, B.S. (2009). Ensaios em Economia Bancária e Transmissão Monetária. Tese de Doutorado. Rio de Janeiro: EPGE/FGV. 
MATSUMOTO, K. (2000). Efeitos Reais da Transmissão de Política Monetária: comparação empírica entre Brasil e Argentina. Dissertação de Mestrado. Rio de Janeiro: EPGE/FGV

MENDONÇA, H.F. (2005). "Metas para inflação e variáveis macroeconômicas: uma avaliação empírica”. Disponível em: www.anpec.org.br/encontro2005/artigos/A05A040.pdf. Acesso em: $01 / 08 / 2008$.

MODENESI, A. (2008). “Convenção e rigidez na política monetária: uma estimativa da função de reação do BCB - 2000-2007”. Texto para Discussão IPEA n. 1351.

MOURA, A. (2006). “Letras Financeiras do Tesouro: quousque tandem”. In: BACHA, E.; OLIVEIRA, L.C. Mercado de Capitais e Divida Pública. Rio de Janeiro: Contra Capa, pp. 45-254.

NAKANE, M.I. (2003). “Concorrência e spread bancário: uma revisão da evidência para o Brasil”. In Banco Central do Brasil, Juros e Spread Bancário no Brasil: Avaliação de 4 Anos do Projeto, pp. 58-67. Brasília: Banco Central do Brasil.

NAKANE, M.I. (2002). “A test of competition in Brazilian banking”. Estudos Econômicos, 32: 203224.

NAKANE, M.I.; COSTA, A.C.A. (2005). "Spread bancário: os problemas da comparação internacional". Risk Update, 1(3): 9-14.

NAKANO, Y. (2005). "O regime monetário e de dívida pública brasileira e a alta taxa de juros”. Revista de Conjuntura Econômica, 59(11): 10-12.

ONO, F.H.; JONAS, G.; OREIRO, J.L.; PAULA, L.F. (2005). “Conversibilidade da conta de capital, taxa de juros e crescimento econômico". Revista de Economia Contemporânea, 9(2): 231-261.

OREIRO, J.L., PAULA, L.F.; JONAS, G. (2004). "Por uma moeda parcialmente conversível: uma crítica a Arida e Bacha". Revista de Economia Política. 24(2): 223-237.

OREIRO, J.L.; LEMOS, B.P.; MISSIO, F.J.; PADILHA, R.A. (2005). "Qual a taxa potencial de crescimento da economia brasileira?”. Revista de Economia, 31(2): 10-35.

PAULA, L.F. (2008). "Financial liberalization, exchange rate regime and economic performance in the BRICs countries”. In: ARESTIS, P.; PAULA, L.F. (org.). Financial Liberalization and Economic Performance in Emerging Countries. Basingstoke: Palgrave Mamillan.

PAULA, L.F.; ALVES JR., A.J. (2003) “Banking behavior and the Brazilian economy after the Real Plan: a post-Keynesian approach”. Banca Nazionale del Lavoro Quaterly Review, 227: 337-365.

PAULA, L.F., OREIRO, J.L.; JONAS, G. (2003). "Fluxos e controle de capitais no Brasil: avaliação e proposição de política”. In SICSÚ, J., OREIRO, J.L.; PAULA, L.F. (org). Agenda Brasil. Barueri, Manole.

PINDYCK, R. S.; RUBINFELD, D.L. (1991). Econometric Models and Economic Forecasts. New York: Mc Graw-Hill.

RAMASWAMY, R., SLOEK, T. (1998). “The real effects of monetary policy in the european union: what are the differences? "IMF Staff Papers, 45(2): 374-396.

RELATÓRIO DE INFLAÇÃO. Banco Central do Brasil, jun. 1999 a mar. 2006 (publicação trimestral). Disponível em: http://www.bcb.gov.br/?RELINF.

RESENDE, A.L. (2006). "Em defesa dos títulos de indexação financeira”. In: BACHA, E.L.; OLIVEIRA, L.C. Mercado de Capitais e Dívida Pública, op.cit.

SAUNDERS, A.; SCHUMACHER, L. (2000). "The determinants of bank interest rate margins: an international study”. Journal of International Money and Finance, 19: 813-832.

SILVA, G.J.C.; OREIRO, J.L.; PAULA, L.F. (2007). "Comportamento do spread bancário no Brasil: uma avaliação empírica recente”. In PAULA, L.F; OREIRO, J.L. (orgs.). Sistema Financeiro: uma análise do setor bancário brasileiro. Campus: Rio de Janeiro.

SIMS, C. (1980). “Macroeconomics and reality”. Econometrica, 48(1): 1-48.

TESOURO NACIONAL. Metodologia de Cálculo dos Títulos Públicos Ofertados no Tesouro Direto. $4^{\circ}$. edição. Disponível em: http://www.tesouro.fazenda.gov.br/tespuro_direto/download/metodologia. pdf. 


\section{ANEXO}

Decomposição da variância do modelo

\begin{tabular}{ccccc}
\multicolumn{5}{c}{ Decomposição da Variância da UTIL. CAP } \\
\hline Lag & SELIC & Câmbio & IPCA. & EXPEC. \\
1 & $\mathbf{7 . 3 0 2 7 7 2}$ & 0.522130 & 0.890222 & 0.047287 \\
2 & $\mathbf{5 . 7 2 2 1 5 6}$ & 0.473076 & 1.643688 & 0.044562 \\
3 & $\mathbf{5 . 2 2 9 4 4 7}$ & 0.842497 & 2.454972 & 1.946825 \\
4 & $\mathbf{5 . 5 5 4 0 3 0}$ & 0.839483 & 2.675578 & 5.397008 \\
5 & $\mathbf{6 . 9 1 1 1 5 4}$ & 0.831583 & 2.781014 & 9.251161 \\
6 & $\mathbf{8 . 3 0 0 3 0 0}$ & 0.964082 & 2.846243 & 11.25734 \\
7 & $\mathbf{9 . 4 2 1 6 4 1}$ & 1.107890 & 2.862070 & 12.15366 \\
8 & $\mathbf{1 0 . 2 3 2 8 9}$ & 1.647965 & 3.525693 & 12.28943 \\
9 & $\mathbf{1 0 . 6 4 9 1 6}$ & 2.767356 & 4.651504 & 12.02998 \\
10 & $\mathbf{1 1 . 0 1 6 0 9}$ & 4.269452 & 5.769616 & 11.59532 \\
11 & $\mathbf{1 1 . 4 1 3 0 7}$ & 5.735062 & 6.820898 & 11.17772 \\
12 & $\mathbf{1 1 . 8 1 9 3 6}$ & 7.023851 & 7.749495 & 10.91755 \\
\hline
\end{tabular}

\begin{tabular}{ccccc}
\multicolumn{5}{c}{ Decomposição da Variância do Câmbio } \\
\hline Lag & UTIL. CAP. & SELIC & IPCA. & EXPEC. \\
1 & 0.000000 & 0.000000 & 0.000000 & 0.000000 \\
2 & 0.017611 & 0.003891 & 1.175067 & 0.840185 \\
3 & 0.101512 & 1.054736 & 1.661294 & 3.209414 \\
4 & 0.139369 & 1.935236 & 6.625343 & 5.271540 \\
5 & 0.124922 & 2.516103 & 10.26404 & 8.060443 \\
6 & 0.141048 & 3.015072 & 13.00785 & 10.97228 \\
7 & 0.168465 & 3.770357 & 14.28525 & 13.97377 \\
8 & 0.186182 & 4.649107 & 15.18348 & 16.64980 \\
9 & 0.191789 & 5.617880 & 15.65350 & 18.95783 \\
10 & 0.204019 & 6.616403 & 15.87860 & 20.83885 \\
11 & 0.225701 & 7.670606 & 15.90092 & 22.28608 \\
12 & 0.255494 & 8.783947 & 15.84565 & 23.26601 \\
\hline
\end{tabular}

Decomposição da Variância do IPCA

\begin{tabular}{|c|c|c|c|c|}
\hline Lag & UTIL. CAP. & SELIC & Câmbio & EXPEC. \\
\hline 1 & 0.000000 & 0.000000 & 5.128872 & 34.21117 \\
\hline 2 & 1.466735 & 0.717295 & 23.10729 & 37.53984 \\
\hline 3 & 1.146991 & 0.578395 & 33.09653 & 36.12847 \\
\hline 4 & 2.003834 & 2.433667 & 37.68286 & 32.25722 \\
\hline 5 & 3.306653 & 3.049344 & 37.69562 & 29.32367 \\
\hline 6 & 4.124764 & 3.134515 & 36.79345 & 27.47087 \\
\hline 7 & 3.772990 & 2.946920 & 35.70545 & 27.45465 \\
\hline 8 & 3.391034 & 2.857788 & 34.73192 & 28.92700 \\
\hline 9 & 3.149266 & 2.954441 & 33.47397 & 30.73428 \\
\hline 10 & 2.996019 & 3.166141 & 32.32879 & 32.49993 \\
\hline 11 & 2.897677 & 3.415252 & 31.36835 & 33.98935 \\
\hline 12 & 2.841865 & 3.690117 & 30.6502 & 35.06138 \\
\hline
\end{tabular}

Decomposição da Variância das EXPECTATIVAS

\begin{tabular}{ccccc}
\hline Lag & UTIL. CAP. & $\begin{array}{c}\text { Câmbio } \\
\text { IPCA }\end{array}$ & \multicolumn{1}{c}{ EXPEC. } \\
1 & 0.000000 & $\mathbf{1 . 2 2 9 9 7 0}$ & $\mathbf{2 . 1 9 0 1 6 8}$ & $\mathbf{0 . 0 0 6 1 5 5}$ \\
2 & 3.849784 & $\mathbf{1 . 3 7 3 8 4 9}$ & $\mathbf{2 . 0 2 9 5 4 4}$ & $\mathbf{1 . 6 0} \mathbf{1 5 2 2}$ \\
3 & 9.123045 & $\mathbf{1 . 1 0 3 7 3 8}$ & $\mathbf{1 . 5 6 5 9 4 7}$ & $\mathbf{3 . 8 9 7 0 6 9}$ \\
4 & 7.523893 & $\mathbf{1 . 6 6 5 5 2 4}$ & $\mathbf{3 . 8 3 1 2 4 0}$ & $\mathbf{7 . 1 7 2 0 3 3}$ \\
5 & 6.656927 & $\mathbf{5 . 6 7 4 1 7 2}$ & $\mathbf{3 . 7 9 4 1 1 0}$ & $\mathbf{7 . 6 0 7 0 1 8}$ \\
6 & 6.187719 & $\mathbf{7 . 7 5 8 8 7 6}$ & $\mathbf{5 . 7 1 6 9 4 0}$ & $\mathbf{7 . 3 2 0 0 4 1}$ \\
7 & 5.508066 & $\mathbf{1 0 . 6 3 6 2 6}$ & $\mathbf{8 . 1 4 2 4 0 6}$ & $\mathbf{6 . 5 9 4 0 5 9}$ \\
8 & 4.953994 & $\mathbf{1 4 . 0 2 2 1 0}$ & $\mathbf{1 0 . 6 0 4 3 9}$ & $\mathbf{5 . 7 8 3 1 2 0}$ \\
9 & 4.480736 & $\mathbf{1 7 . 1 7 9 3 0}$ & $\mathbf{1 2 . 7 7 2 1 3}$ & $\mathbf{5 . 1 3 5 5 2 7}$ \\
10 & 4.028628 & $\mathbf{1 9 . 6 6 0 5 9}$ & $\mathbf{1 4 . 6 6 7 0 1}$ & $\mathbf{4 . 9 0 7 0 4 6}$ \\
11 & 3.663034 & $\mathbf{2 1 . 4 4 8 8 9}$ & $\mathbf{1 6 . 1 6 2 0 5}$ & $\mathbf{5 . 1 3 7 8 2 7}$ \\
12 & 3.345421 & $\mathbf{2 2 . 5 9 1 7 1}$ & $\mathbf{1 7 . 3 9 3 7 8}$ & $\mathbf{5 . 7 0 8 0 6 2}$ \\
\hline
\end{tabular}

Decomposição da Variância da SELIC.

\begin{tabular}{|c|c|c|c|c|}
\hline Lag & UTIL. CAP. & SELIC & Câmbio & $I P C A$ \\
\hline 1 & 0.000000 & 0.000000 & 2.067525 & 0.000000 \\
\hline 2 & $1.78 \mathrm{E} \quad-05$ & 0.009216 & 14.35908 & 0.477115 \\
\hline 3 & 0.180325 & 0.658865 & 31.21614 & 1.049727 \\
\hline 4 & 1.031496 & 2.043493 & 41.20667 & 1.236760 \\
\hline 5 & 1.911634 & 3.001060 & 46.10220 & 5.661138 \\
\hline 6 & 1.969813 & 3.083530 & 47.51282 & 12.89402 \\
\hline 7 & 1.627972 & 2.993208 & 47.89120 & 17.78482 \\
\hline 8 & 1.335065 & 3.109022 & 47.30053 & 20.06910 \\
\hline 9 & 1.142934 & 3.492981 & 45.83562 & 20.87765 \\
\hline 10 & 1.013890 & 4.027703 & 43.87248 & 21.02406 \\
\hline 11 & 0.921874 & 4.615779 & 41.85119 & 20.81760 \\
\hline 12 & 0.862178 & 5.226697 & $40.0395 \quad 9$ & 20.45589 \\
\hline
\end{tabular}

